\title{
Papers
}

\section{Exercises to prevent lower limb injuries in youth sports: cluster randomised controlled trial}

Odd-Egil Olsen, Grethe Myklebust, Lars Engebretsen, Ingar Holme, Roald Bahr

\begin{abstract}
Objective To investigate the effect of a structured warm-up programme designed to reduce the incidence of knee and ankle injuries in young people participating in sports.

Design Cluster randomised controlled trial with clubs as the unit of randomisation.

Setting 120 team handball clubs from central and eastern Norway (61 clubs in the intervention group, 59 in the control group) followed for one league season (eight months). Participants 1837 players aged 15 - 17 years; 958 players $(808$ female and 150 male) in the intervention group; 879 players (778 female and 101 male) in the control group.

Intervention A structured warm-up programme to improve running, cutting, and landing technique as well as neuromuscular control, balance, and strength.

Main outcome measure The rate of acute injuries to the knee or ankle.

Results During the season, 129 acute knee or ankle injuries occurred, 81 injuries in the control group (0.9 (SE 0.09) injuries per 1000 player hours; 0.3 (SE 0.17) in training $v 5.3$ (SE 0.06) during matches) and 48 injuries in the intervention group $(0.5$ (SE 0.11) injuries per 1000 player hours; 0.2 (SE 0.18) in training $v 2.5$ (SE 0.06) during matches). Fewer injured players were in the intervention group than in the control group (46 $(4.8 \%) v(76(8.6 \%)$; relative risk intervention group $v$ control group $0.53,95 \%$ confidence interval 0.35 to 0.81 ).

Conclusion A structured programme of warm-up exercises can prevent knee and ankle injuries in young people playing sports. Preventive training should therefore be introduced as an integral part of youth sports programmes.
\end{abstract}

\section{Introduction}

Regular physical activity reduces the risk of premature mortality in general and of coronary heart disease, hypertension, colon cancer, obesity, and diabetes mellitus in particular. ${ }^{2}$ However, participation in sports also entails a risk of injury for all athletes, from the elite to the recreational level. Studies from Scandinavia document that sports injuries constitute $10-19 \%$ of all acute injuries seen in emergency departments, and the most common types are knee and ankle injuries. ${ }^{3}$ Serious knee injuries, such as injuries to the anterior cruciate ligament, are a growing cause of concern. The highest incidence is seen in adolescents playing pivoting sports such as football, basketball, and team handball. In these sports, women are three to five times more likely to contract a serious knee injury than men. ${ }^{4-6}$

Injuries to the anterior cruciate ligament may require surgery, always entail a long rehabilitation period, and drastically increase the risk of long term sequelae. ${ }^{7}$ Although treatment methods have advanced notably, there is no evidence to show that repair of a ruptured anterior cruciate ligament or isolated cartilage lesions prevents early development of osteoarthritis. ${ }^{7}$ Effective methods for preventing injuries therefore need to be developed.

Some studies report promising results, indicating that it may be possible to reduce the incidence of knee and ankle injuries among adults ${ }^{8-10}$ and adolescents. ${ }^{11-14}$ However, these studies are small and mainly non-randomised, with important methodological limitations. Prospective randomised intervention studies are therefore needed, especially among children and adolescents, to assess the efficacy of interventions aiming to reduce injuries.

We conducted a randomised controlled trial to investigate the effect of a structured programme of warm-up exercises used to prevent acute injuries of the lower limb in young people playing sports. To minimise overlap within clubs, we used a cluster design.

\section{Methods}

One hundred and twenty three clubs agreed to participate in the study, and we block randomised these, with four clubs in each block to an intervention or control group. To reduce potential confounding, we matched the clubs by region, playing level, and sex and number of players. The statistician (IH) who conducted the randomisation was not involved in the intervention. Box 1 gives details of the procedure used to recruit clubs.

We informed clubs allocated to the intervention group that they would receive a programme of warm-up exercises used to prevent injuries. We asked the clubs in the control group to do their training as usual during the season and informed them that they would receive the same programme as the intervention group at the start of the subsequent season.

\section{Box 1: Recruiting clubs to the study}

- All 145 clubs in the 16 year and 17 year divisions from central and eastern Norway, organised by the Norwegian Handball Federation, received an invitation to participate in the study during one eight month season (September 2002 to April 2003)

- The clubs practised one to five times per week and played between 20 and 50 matches during the season, depending on their ability and ambition

- The clubs were recruited from June to August 2002 through the website of the Norwegian Handball Federation, and a letter with information about the purpose and the design of the study went to the coaches, who also informed the players 


\section{Intervention}

The warm-up programme was developed by medical staff from the Oslo Sports Trauma Research Center and coaching staff from the Norwegian Handball Federation, and its feasibility had been tested in four clubs during the previous season. The programme included four different sets of exercises, each of increasing difficulty.

At the start of the league season (September), the clubs in the intervention group received one visit from an instructor from the handball federation. In addition, instructors followed up the clubs with a visit midway through the season (January). The instructors had been familiarised with the programme during a two hour seminar, in which they received theoretical and practical training on how to conduct the programme. The clubs received an exercise book, five wobble boards (disc diameter 38 cm; Norpro, Notodden, Norway, 2000) and five balance mats $\left(40 \times 50 \mathrm{~cm}^{2}, 7 \mathrm{~cm}\right.$ thick; Alusuisse Airex, Sins, Switzerland, 2000). The coaches were asked to use the programme at the beginning of every training session for 15 consecutive sessions and then once a week during the remainder of the season.

The main focus of the exercises was to improve awareness and control of knees and ankles during standing, running, cutting, jumping, and landing. The programme consisted of exercises with the ball, including the use of the wobble board and balance mat (box 2, fig 1, and fig 2), for warm up, technique, balance, and strength.

The players were encouraged to be focused and conscious of the quality of their movements, with emphasis given to core stability and position of the hip and knee in relation to the foot (the

Box 2: Programme of warm-up exercises used to prevent injuries

Warm-up exercises

(30 seconds and one repetition each)

Jogging end to end

Backward running with sidesteps

Forward running with knee lifts and heel kicks

Sideways running with crossovers ("carioca")

Sideways running with arms lifted ("parade")

Forward running with trunk rotations

Forward running with intermittent stops

Speed run

\section{Technique}

(One exercise during each training session; 4 minutes and $5 \times 30$ seconds each)

Planting and cutting movements

Jump shot landings

\section{Balance}

(On a balance mat or wobble board, one exercise during each training session; 4 minutes and $2 \times 90$ seconds each)

Passing the ball (two leg stance)

Squats (one or two leg stance)

Passing the ball (one leg stance)

Bouncing the ball with eyes closed

Pushing each other off balance

\section{Strength and power}

( 2 minutes and $3 \times 10$ repetitions each)

One quadriceps exercise:

Squats to $80^{\circ}$ of knee flexion

Bounding strides (Sprunglauf)

Forward jumps

Jump shot-two legged landing

"Nordic hamstring lowers" ( 2 minutes and $3 \times 10$ repetitions each) "knee over toe" position). They were also asked to watch each other closely and give each other feedback during the training. They were instructed to spend 4-5 minutes on each exercise group for a total duration of 15-20 minutes.

Data on injury and exposure were reported by the physiotherapists using a web based database in which all the data were coded anonymously. At the end of the season, the recorded data were confirmed, or if necessary corrected, by the coaches. Box 3 shows the definitions we used in registering injuries.

\section{Outcome measures}

We defined the primary outcome as an acute injury to the knee or ankle. A secondary outcome was defined as any injury to the lower limbs. We also included secondary analyses of injuries overall (including all injuries) and injuries to the upper limb. We included all injuries reported after an intervention club had completed the first session of the training aiming to prevent injuries (and from the same date in the control clubs randomised in the same block), to compare the number of injured players and incidence of injury between the intervention group and the control group.

The number of injured players was based on data from individual players and the incidence of injuries on summary data of injuries and exposures for the whole group. Data on players who dropped out during the study period were included for the entire period of their participation.

Ten research physiotherapists who were blinded to group allocation recorded injuries in both groups, using definitions (box 3) and a standardised injury questionnaire described in our earlier study (Olsen OE, Myklebust G, Engebretsen L, Bahr R. Injury pattern in youth team handball: a comparison of two prospective registration methods. Submitted for publication to Scand JMed Sci Sports).

The physiotherapists were in contact with the coaches at least every month to record injured players and exposure data. They interviewed injured players, either in person or by telephone, and in most cases within four weeks (range one day to four months). They were responsible for roughly the same number of clubs from each of the groups (11 to 13 clubs each).

The coaches of the clubs receiving the intervention recorded compliance on a designated form as the number of injury prevention sessions, the duration of each session in minutes, and the average attendance of the players (in per cent). At the end of the season we also obtained information on prevention training conducted by the control clubs, including the types and volume of exercises used.

\section{Sample size}

In youth team handball, the incidence of acute injuries to the knee and ankle is estimated to be 12 per 100 players per league season. ${ }^{115}$ From a pilot study conducted to determine the incidence of injury during the previous season (submitted for publication), we estimated that the cluster effects for club randomisation gave an inflation factor of 2.0 based on a cluster size of 15 and an intracluster correlation coefficient of 0.07 . We then calculated that to achieve $90 \%$ power with $\alpha=5 \%$ to detect a relative risk reduction of $50 \%$, we would need 915 players in each group. Therefore, when we initiated the trial, we were hoping to include 60 clubs in each group (a total of 120 clubs; with an average of 15 players in each club).

\section{Statistical methods}

We used Stata, version 8.0 (Stata Corporation, Lakeway Drive, Texas, 2003), for the statistical analysis. We undertook all statistical analyses according to a prespecified plan. We used the 


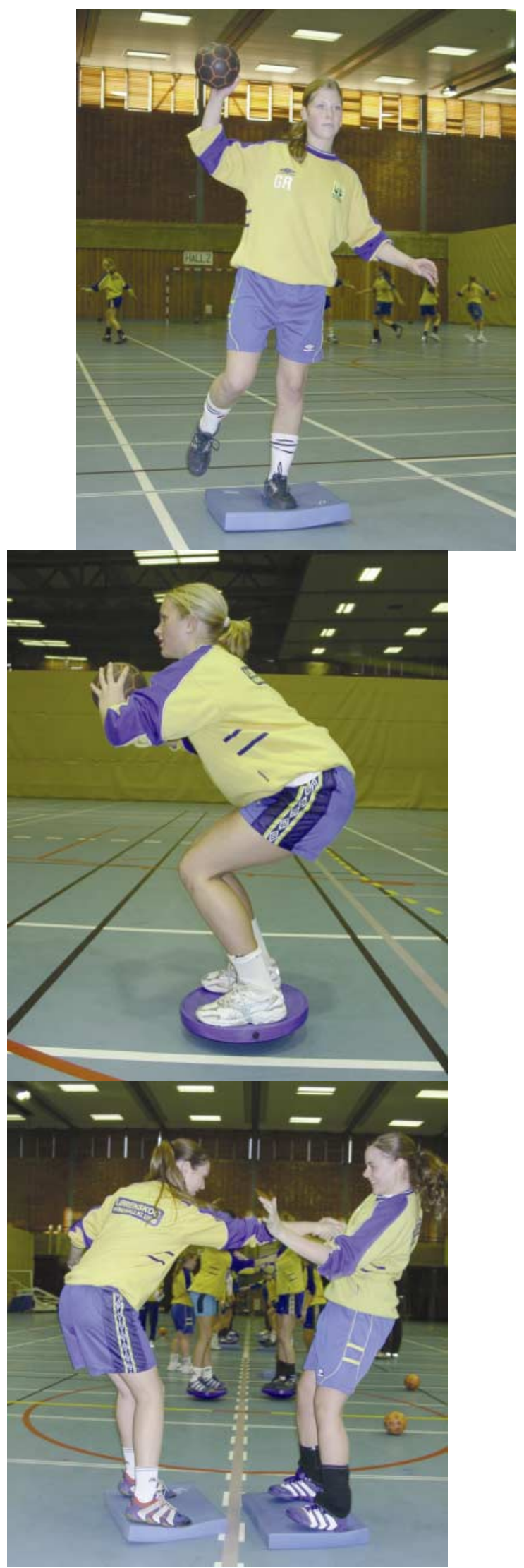

Fig 1 Top: mat exercise. Middle: wobble board exercise. Bottom: mat pair exercise

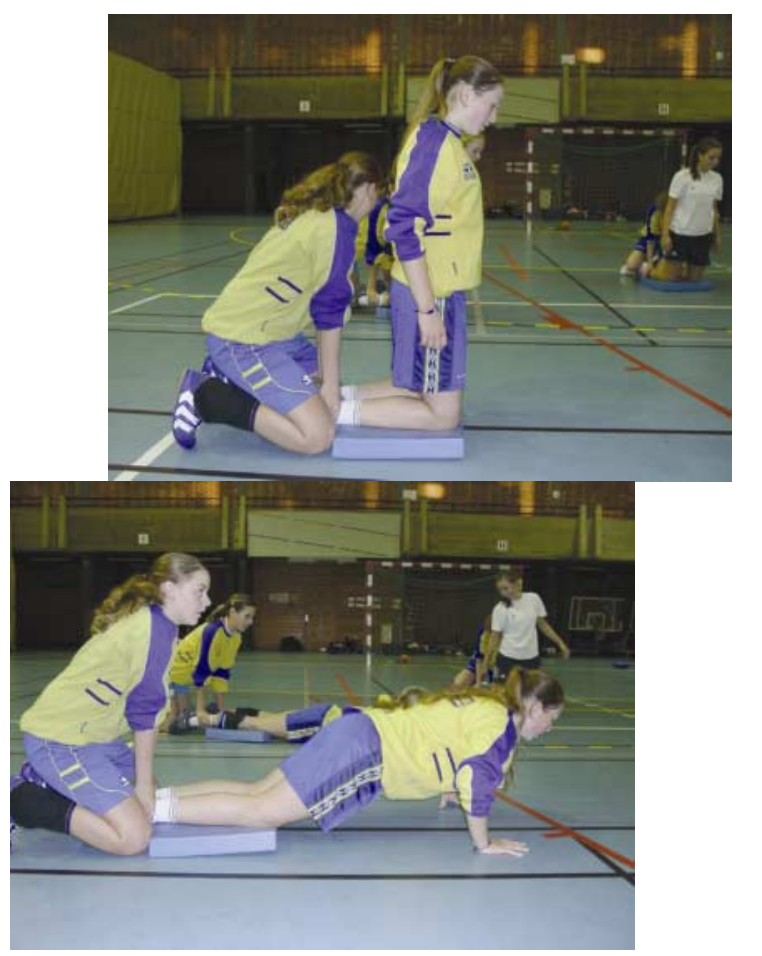

Fig 2 Example of a strength exercise ("Nordic hamstring lowers"). Top: start position; a partner holds around the player's ankles. Bottom: The player falls slowly forwards, using hamstrings to resist the fall against the floor as long as possible

relative risk of the number of injured players according to the intention to treat principle to compare the risk of an injury in the intervention and control groups. Cox regression was our analysis tool for the primary outcome as well as the secondary outcomes, and we used the robust calculation method of the variance-covariance matrix, ${ }^{16}$ taking into account the cluster randomisation. We tested rate ratios with Wald's test. We used one way analysis of variance to estimate the intracluster correlation coefficient to obtain estimates of the inflation factor for comparison with planned sample size. We used the inverse of the difference between percentages of injured players in the two groups to calculate the number needed to treat to save one injury. We calculated exposures to training and matches and incidence of injury as described in our earlier study.

We used a $\mathrm{z}$ test based on the Poisson model to compare the rate ratio between the two groups (intervention $v$ control), sex (female $v$ male), severity of injury (slight, minor, moderate, major), and club activities (match, training).

Compliance and incidence of injury are presented as means with standard errors. Relative risk and rate ratio are presented with $95 \%$ confidence intervals. We regarded two tailed $\mathrm{P}$ values $\leq 0.05$ as significant.

\section{Results}

Figure 3 shows the flow of clubs and players through the trial. Players in the two groups were similar in sex distribution, age, and dropout rates (table 1). All but eight (13\%) of the clubs in the intervention group used the programme of warm-up exercises used to prevent injuries during the study period. Also, 13 (22\%) of the clubs in the control group used specific exercises intended to prevent injuries (including training on the balance mat and wobble board) as a part of their training. 
Table 1 Characteristics of participants and compliance of clubs. Values are numbers (percentages) of participants unless otherwise indicated

\begin{tabular}{|c|c|c|}
\hline Characteristic & Intervention group ( $\mathrm{n}=958$ ) & Control group $(n=879)$ \\
\hline Girls & $808(50.9)$ & $778(49.1)$ \\
\hline Boys & $150(59.8)$ & $101(40.2)$ \\
\hline Mean (SD) age in years* & $16.3(0.6)$ & $16.2(0.6)$ \\
\hline Dropouts & $68(7.1)$ & $51(5.8)$ \\
\hline \multicolumn{3}{|l|}{ Injury prevention programme: } \\
\hline Clubs & $61 \dagger$ & 13 \\
\hline $\begin{array}{l}\text { Training sessions (SE, } \\
\text { range) }\end{array}$ & $27(12,1-55) \ddagger$ & $26(7,14-35) \S$ \\
\hline $\begin{array}{l}\text { Average time spent per } \\
\text { session in minutes (SE) }\end{array}$ & $18(6)$ ๆ & $18(9)^{\star \star}$ \\
\hline $\begin{array}{l}\text { Average attendance per } \\
\text { session in \% }\end{array}$ & $73+\dagger$ & 81㧊 \\
\hline
\end{tabular}

${ }^{*}$ Range $15-17$ years in both groups.

†Eight $(13 \%)$ of the clubs did not continue using the programme of warm-up exercises used to prevent injuries after the initial intensive introduction period. They used the programme at 5 (SE 5, range 1-13) sessions during the first part of the season and then discontinued the programme.

\$14 (SE 7, 1-30) in the first part of the season (September to December) and 13 (SE 7, 0-26) in the second part (January to April).

$\S 14$ (SE 4, 7-20) in the first part and 12 (SE 3, 7-15) in second part.

१20 (SE 5) in the first part $v 16$ (SE 7) in second part.

**18 (SE 9) minutes in both first and second part.

$\$ \neq 78 \%$ in the first part $v 69 \%$ in second part.

†† $85 \%$ in the first part $v 78 \%$ in second part.

Box 3: Operational definitions used in the registration of injury

\section{Reportable injury}

An injury occurred during a scheduled match or training session, causing the player to require medical treatment or miss part of or the next match or training session

\section{Player}

A player was entered into the study if she or he was aged 15-17

years (born between 1 January 1985 and 31 December 1987),

was registered on the club roster by the coach, and did not have a major injury at the start of the study

\section{Return to participation}

The player was defined as injured until he or she was able to participate fully in club activities (match and training sessions)

\section{Type of injury}

Acute-injury with a sudden onset associated with a known trauma

Overuse-injury with a gradual onset without any known trauma

Severity $\dagger$

Slight -0 days of absence and able to participate fully in the next match or training session

Minor-absence from match or training for 1-7 days

Moderate-absence from match or training for 8-21 days

Major-absence from match or training for $>21$ days

Exposure*

Match exposure-hours of matches

Training exposure-hours of training

In nearly all cases, players sustaining moderate or major injuries

were examined by a doctor. If there was any doubt about the diagnosis the player was referred to a sport doctor or a sports medicine centre for follow up, which often included imaging studies or arthroscopic examination. In case of a slight or minor injury, the player was often examined only by a physical therapist or coach or not at all. None of the injured players was examined or treated by any of the authors, and we had no influence on the time it took a player to return to club activities.

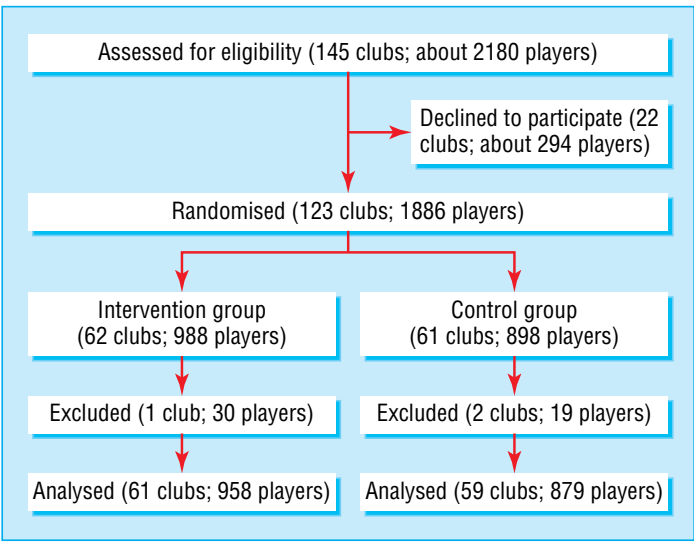

Fig 3 Flow of club clusters and players through the study. After randomisation, two clubs in the control group withdrew from participating in the Norwegian Handball Federation league (no players played for these clubs), and one club in the intervention group declined to participate in the study. The players $(n=49)$ in these clubs were excluded from the study

\section{Injury characteristics}

During the eight month season, 262 (14\%) of the 1837 players who were included in the study contracted a total of 298 injuries. Of these, $241(81 \%)$ were acute injuries and $57(19 \%)$ were overuse injuries. Table 2 shows the location of the most common body part injured, the type of acute and overuse injuries, and the age of the injured players.

\section{Effect of prevention}

Significantly fewer injured players were in the intervention group than in the control group for injuries overall, lower limb injuries, acute knee or ankle injuries, and acute knee and upper limb injuries, whereas a $37 \%$ reduction in acute ankle injuries did not reach significance (table 3 ). The degrees of clustering at the club level (intracluster correlation coefficient) were estimated to be 0.043 to 0.071 . The number needed to treat to prevent one injury varied from 11 to 59 players.

The exposure in hours for the intervention group was 93812 (11 210 hours spent in matches, 82602 hours in training) and in the control group 87483 hours (10 783 hours in matches,

Table 2 Most common body part injured, most common type of acute and overuse injuries, and age of the injured players. Values are numbers (percentages) of participants unless otherwise indicated

\begin{tabular}{lcc}
\multicolumn{1}{c}{ Intervention group (n=958) } & Control group (n=879) \\
\hline Body category: & $31(30.1)$ & $47(24.1)$ \\
\hline Ankle & $25(24.3)$ & $44(22.6)$ \\
\hline Knee & $10(9.7)$ & $22(11.3)$ \\
\hline Finger & $7(6.8)$ & $11(5.6)$ \\
\hline Head & $7(6.8)$ & $9(4.6)$ \\
\hline Low back & $4(3.9)$ & $11(5.6)$ \\
\hline Shoulder & & $75(48.1)$ \\
\hline Acute injuries: & $48(56.5)$ & $30(19.2)$ \\
\hline Sprains & $15(17.6)$ & $18(11.5)$ \\
\hline Contusions & $8(9.4)$ & $11(7.1)$ \\
\hline Fractures & $6(7.1)$ & $20(51.3)$ \\
\hline Strains & & $6(15.4)$ \\
\hline Overuse injuries: & $5(27.8)$ & $5(12.8)$ \\
\hline $\begin{array}{l}\text { Anterior lower leg pain } \\
\text { (periostitis) }\end{array}$ & $5(27.8)$ & $17.1(0.7)$ \\
\hline Knee pain & $3(16.7)$ & \\
\hline Low back pain & $17.3(0.7)$ & \\
\hline Mean (SD) age of injured & & \\
players in years*
\end{tabular}

players in years*

${ }^{*}$ Range $15-18$ years in both groups. 
Table 3 Intention to treat analysis. Values are numbers (percentages) of injured players

\begin{tabular}{|c|c|c|c|c|c|c|c|}
\hline & $\begin{array}{l}\text { Intervention group } \\
\quad(\mathrm{n}=958)\end{array}$ & $\begin{array}{l}\text { Control group } \\
\qquad(\mathrm{n}=879)\end{array}$ & $\begin{array}{c}\text { Intracluster } \\
\text { correlation coefficient }\end{array}$ & Inflation factor & $\begin{array}{l}\text { Number } \\
\text { needed to } \\
\text { treat }\end{array}$ & Relative risk $(95 \% \mathrm{Cl})^{*}$ & $\begin{array}{c}\text { P value (Wald's } \\
\text { test) }\end{array}$ \\
\hline All injuries & $95(9.9)$ & $167(19.0)$ & 0.043 & 1.6 & 11 & 0.49 (0.36 to 0.68$)$ & $<0.0001$ \\
\hline Lower limb injuries & $66(6.9)$ & $115(13.1)$ & 0.050 & 1.7 & 16 & 0.51 (0.36 to 0.73$)$ & $<0.001$ \\
\hline Acute knee or ankle injuries: & $46(4.8)$ & $76(8.6)$ & 0.057 & 1.8 & 26 & 0.53 (0.35 to 0.81$)$ & 0.004 \\
\hline Acute knee injuries & $19(2.0)$ & $38(4.3)$ & 0.071 & 2.0 & 43 & 0.45 (0.25 to 0.81$)$ & 0.007 \\
\hline Acute ankle injuries & $28(2.9)$ & $40(4.6)$ & 0.071 & 2.0 & 59 & 0.63 (0.36 to 1.09$)$ & 0.097 \\
\hline Upper limb injuries & $17(1.8)$ & $39(4.4)$ & 0.071 & 2.0 & 38 & 0.37 (0.20 to 0.69$)$ & 0.002 \\
\hline
\end{tabular}

${ }^{*}$ Cox model calculated according to method of Lin and Wei, ${ }^{17}$ which takes cluster randomisation into account.

76700 hours in training). Table 4 shows the severity of injury for different types of injury. Injuries overall, acute injuries, and acute knee or ankle injuries differed significantly, whereas reductions in 7-53\% for slight injuries and $18-59 \%$ in minor injuries did not reach significance. The overall difference in the incidence of match and training injuries was also significant, whereas acute injuries and acute knee or ankle injuries differed only for matches (table 5). The 13 control clubs using training exercises to prevent injuries had a significantly lower incidence of injuries than the clubs in the control group doing no prevention training (rate ratio: all injuries $0.48,95 \%$ confidence interval 0.31 to 0.73 , $\mathrm{P}<0.001$; lower limb injuries $0.35,0.19$ to $0.63 ; \mathrm{P}=0.001$; acute injuries $0.47,0.29$ to $0.76 ; \mathrm{P}=0.002$; acute knee or ankle injuries $0.22,0.09$ to $0.55 ; \mathrm{P}=0.001)$. No category of injury differed by sex.

\section{Discussion}

The rate of injuries in adolescent athletes using a structured warm-up programme as a part of their training improved clinically and statistically, especially the rate of severe injuries to the knee and ankle. The reduction in the relative risk is highly significant and has been adjusted for the cluster sampling, which takes into account the analytical limitations of a cluster randomised study. As far as we are aware, our study is the first randomised controlled trial among adolescents with a sufficient sample size to show that acute knee or ankle injuries can be reduced by $50 \%$ and severe injuries even more.

\section{Data validation}

The trial took place in the divisions comprising 16 year and 17 year olds from large geographical regions of Norway and

Table 4 Numbers and severity of injuries

\begin{tabular}{|c|c|c|c|c|}
\hline & Intervention group $(\mathrm{n}=958)$ & Control group ( $n=879$ ) & Rate ratio $(95 \% \mathrm{Cl})^{*}$ & $P$ value $(z$ test $)$ \\
\hline All injuries: & 103 & 195 & 0.49 (0.39 to 0.63$)$ & $<0.0001$ \\
\hline Match & 56 & 112 & 0.48 (0.35 to 0.66$)$ & $<0.0001$ \\
\hline Training & 47 & 83 & $0.53(0.37$ to 0.75$)$ & $<0.001$ \\
\hline Slight & 4 & 8 & $0.47(0.14$ to 1.55$)$ & 0.21 \\
\hline Minor & 47 & 62 & 0.71 (0.48 to 1.03$)$ & 0.07 \\
\hline Moderate & 20 & 56 & $0.33(0.20$ to 0.55$)$ & $<0.0001$ \\
\hline Major & 32 & 69 & $0.43(0.28$ to 0.66$)$ & $<0.0001$ \\
\hline Overuse injuries: & 18 & 39 & $0.43(0.25$ to 0.75$)$ & 0.003 \\
\hline Slight & 0 & 3 & - & - \\
\hline Minor & 4 & 9 & 0.41 (0.13 to 1.35$)$ & 0.14 \\
\hline Moderate & 7 & 12 & 0.54 (0.21 to 1.38) & 0.2 \\
\hline Major & 7 & 15 & 0.44 (0.18 to 1.07) & 0.07 \\
\hline Acute injuries: & 85 & 156 & 0.51 (0.39 to 0.66$)$ & $<0.0001$ \\
\hline Slight & 4 & 5 & $0.76(0.20$ to 2.78$)$ & 0.66 \\
\hline Minor & 43 & 53 & 0.75 (0.51 to 1.13) & 0.17 \\
\hline Moderate & 13 & 44 & 0.28 (0.15 to 0.51$)$ & $<0.0001$ \\
\hline Major & 25 & 54 & 0.43 (0.27 to 0.69$)$ & 0.001 \\
\hline Contact & 51 & 82 & 0.58 (0.41 to 0.82$)$ & 0.002 \\
\hline Non-contact & 34 & 74 & $0.43(0.29$ to 0.64$)$ & $<0.0001$ \\
\hline Acute knee or ankle injuries: & 48 & 81 & 0.55 (0.39 to 0.79$)$ & 0.001 \\
\hline Slight & 3 & 3 & 0.93 (0.19 to 4.62) & 0.93 \\
\hline Minor & 22 & 25 & $0.82(0.46$ to 1.46$)$ & 0.5 \\
\hline Moderate & 8 & 25 & $0.30(0.13$ to 0.66$)$ & 0.003 \\
\hline Major & 15 & 28 & $0.50(0.27$ to 0.94$)$ & 0.03 \\
\hline Knee ligament injuries & $3 \dagger \ddagger$ & $14 \ddagger \S$ & $0.20(0.06$ to 0.70$)$ & 0.01 \\
\hline Meniscus injuries & 2 & 7 & $0.27(0.06$ to 1.28$)$ & 0.1 \\
\hline Players with two or more injuries & 8 & 19 & $0.39(0.17$ to 0.90$)$ & 0.03 \\
\hline Re-injuryף & 0 & 3 & - & - \\
\hline
\end{tabular}

*Rate ratio obtained from Poisson model.

†Anterior cruciate ligament: $n=3$.

fAnterior cruciate ligament $(n=10)$, posterior cruciate ligament $(n=3)$, medial collateral ligament $(n=1)$.

$\$ 10$ of the 16 ligament injuries to the cruciate ligament also included concomitant injuries to the medial collateral ligament, lateral collateral ligament, bone bruise, or meniscus injuries, or a combination of these.

ISame type and location of injury. 
Table 5 Number of acute injuries, acute knee or ankle injuries, and incidence of injuries during matches and training. Incidence is reported as the number of injuries per 1000 player hours, with standard errors

\begin{tabular}{|c|c|c|c|c|c|c|}
\hline & \multicolumn{2}{|c|}{ Intervention group ( $\mathrm{n}=958$ ) } & \multicolumn{2}{|c|}{ Control group ( $n=879$ ) } & \multirow[t]{2}{*}{ Rate ratio $(95 \% \mathrm{Cl})^{*}$} & \multirow{2}{*}{$P$ value ( $z$ test) } \\
\hline & Injuries & Incidence & Injuries & Incidence & & \\
\hline No of acute injuries: & 85 & $0.9(0.08)$ & 156 & $1.8(0.06)$ & $0.51(0.39$ to 0.66$)$ & $<0.0001$ \\
\hline Match & 53 & $4.7(0.06)$ & 111 & $10.3(0.04)$ & 0.46 (0.33 to 0.64$)$ & $<0.0001$ \\
\hline Training & 32 & $0.4(0.14)$ & 45 & $0.6(0.12)$ & $0.66(0.42$ to 1.04$)$ & 0.07 \\
\hline No of acute knee or ankle injuries: & 48 & $0.5(0.11)$ & 81 & $0.9(0.09)$ & 0.55 (0.39 to 0.79$)$ & 0.001 \\
\hline Match & 28 & $2.5(0.06)$ & 57 & $5.3(0.06)$ & $0.47(0.30$ to 0.74$)$ & 0.001 \\
\hline Training & 20 & $0.2(0.18)$ & 24 & $0.3(0.17)$ & 0.78 (0.43 to 1.41$)$ & 0.41 \\
\hline
\end{tabular}

*Rate ratio obtained from Poisson model.

recruited $85 \%$ of eligible players organised by the Norwegian Handball Federation in these areas.

The external validity of the trial should therefore be high. As we found no differences between the two groups at baseline, in dropout rates, and in exposure during the study, the internal validity should also be high. We discussed the reliability and validity of injury and exposure registration in detail in an earlier study, and our method should ensure good reliability and validity of the injury and exposure data and also good reliability for comparing the data between the intervention and the control groups.

\section{Compliance}

On comparison with a previous study that investigated the prevention of injuries to the anterior cruciate ligament at the senior level, ${ }^{10}$ we found a considerably higher compliance $(87 \%)$ among the youth clubs. In view of the media attention focusing on the problem of injuries to the anterior cruciate ligament in women's team handball, we were surprised to find that only $29 \%$ of the clubs participating in a similar non-randomised study of adult players fulfilled the compliance criteria. ${ }^{10}$ However, this study, and our intervention study, may have motivated some of the youth clubs to include exercises to prevent injuries as a regular part of their training programme, as evidenced by the crossover observed in $22 \%$ of the control clubs. In support of the study findings, these clubs had a significantly lower incidence of injuries than the other control clubs. Also, not all clubs continued to use the programme of warm-up exercises used to prevent injuries after the initial intensive introduction period. However, we included all the clubs in an intention to treat analysis, which means that the effect of the programme may be even higher than we have reported.

\section{Structured programme of warm-up exercises to prevent injuries}

The exercises used in the programme were developed on the basis of previous intervention studies in team handball ${ }^{10}{ }^{11}$ and other sports, ${ }^{8-9} 12$ and had been feasibility tested and modified to be suitable for team handball. The focus on alignment of the hip, knee, and ankle- especially the knee over toe position-was supported by data from Ebstrup and Boysen-Moller ${ }^{17}$ and Olsen et al. ${ }^{18}$ Their video analyses of the mechanisms for injuries of the anterior cruciate ligament in team handball indicate that players could benefit from not allowing the knee to sag medially during plant and cut movements or when suddenly changing speed. The programme therefore focused on the proper technique for planting and cutting movements, aiming at a narrower stance as well as a knee over toe position. Recent data from a study investigating the prevention of injuries to the anterior cruciate ligament among adult women's team handball players indicate that a programme of balance and cutting exercises focusing on knee control not only prevents injuries ${ }^{10}$ but also improves dynamic balance and that this effect is maintained for at least 12 months. ${ }^{19}$ One randomised study from senior men's elite soccer also showed a substantial decrease in the rate of injuries to the anterior cruciate ligament as a result of a static balance training programme using a balance board. ${ }^{8}$

The prevention programme that we tested is multifaceted and considers many aspects that could be related to the risk for injury (agility, balance, strength, awareness of vulnerable positions of the knee and ankle, playing technique), and it is not possible to determine exactly which part of the programme may be effective in preventing injuries to the knee and ankle. Based on data from volleyball, ${ }^{20}$ our programme also focused on landing on both legs after jumps rather than just one leg, and with an emphasis on increased hip and knee flexion to attenuate the landing. The programme also included a strength exercise, the "Nordic hamstring lower" exercise, which has been shown to be effective in improving eccentric hamstring muscle strength among adult male soccer players. ${ }^{21}$ Since the hamstrings can act as agonists to the anterior cruciate ligament during stop and jump tasks, ${ }^{20} 22{ }^{23}$ it is possible that stronger hamstring muscles can prevent injuries to the ligament, but this theory has never been tested. Further studies are needed to determine what the key component(s) of the programme are in reducing risk of injury, and it seems warranted to examine the physiological effects of each programme component, as well as the effect on injury risk. In this way it may be possible to develop even more specific programmes that require less time and effort and may be suitable for "weekend recreational" athletes too.

Although injuries to the anterior cruciate ligament are a particular concern, especially in women's pivoting sports, it was not possible to plan this investigation on young players to determine the effect of the intervention programme on rates of injury to the anterior cruciate ligament alone. Our power calculations indicated that a study looking at ruptures of the anterior cruciate ligament would have needed 12000 players in each group to detect a $50 \%$ reduction in such injuries. Even so, we found an $80 \%$ reduction in ruptures of knee ligaments (anterior cruciate ligament, posterior cruciate ligament, and medial collateral ligament) in the intervention group, which reached significance.

\section{Generalisability}

We used youth team handball (age 15-17) as a case of youth sports in our trial. Since the intervention was implemented for both sexes and at different levels, the result indicates that the youth elite as well as the intermediate and recreational players would benefit from using the warm-up programme to prevent injuries. We do not know if the results can be generalised to other age groups or to other youth sports such as football, basketball, or volleyball. However, these sports have a high incidence and similar pattern of knee and ankle injuries, and the injury mechanisms are also comparable (most injuries resulting from pivoting and landing movements). Therefore it seems reasonable to 


\section{What is already known on this topic}

Sports injuries constitute $10-19 \%$ of all acute injuries treated in emergency departments, with injuries to the knee and ankle the most common types

The risk of serious knee injuries, such as injuries to the anterior cruciate ligament, is high among adolescents playing pivoting sports such as football, basketball, or team handball

It may be possible to reduce the incidence of knee and ankle injuries among young people, but studies showing this have been small and mainly non-randomised, with significant methodological limitations

\section{What this study adds}

A structured warm-up programme designed to improve awareness and knee and ankle control during landing and pivoting movements prevents knee and ankle injuries among youth athletes

The incidence of knee and ankle injuries can be reduced by at least $50 \%$

Preventive training should be routine in training programmes for adolescents in pivoting sports

assume that the prevention programme used in the present study also could be modified to be used in other similar sports. Moreover, if the goal is to develop movement patterns that are more resistant to injury, it may be easier to work with even younger players who have not yet established their motion patterns. Therefore, we suggest that programmes focusing on technique (cutting and landing movements) and balance training (on wobble boards, mats or similar equipments) are implemented in players as young as 10-12 years.

\section{Conclusion}

A structured warm-up programme designed to improve awareness and control of knees and ankles during landing and pivoting movements reduces injuries to the lower limb in youth team handball. Preventive training should therefore be introduced as a natural part of youth sports training programmes in similar pivoting sports.

Acknowledgements: We thank the physiotherapists, instructors, coaches, and players who participated in this study and Norwegian Handball Federation staff and officials for practical support.

Contributors: OEO, GM, LE, IH, and RB contributed to study conception and design. OEO coordinated the study and managed all aspects of the trial, including developing, testing, and finalising the intervention, and data collection. IH conducted and initialised the blinded data analyses, which were planned and checked with OEO. OEO and RB wrote the first draft of the paper, and all authors contributed to the final manuscript. OEO is guarantor.

Funding: The Oslo Sports Trauma Research Center has been established at the Norwegian University of Sport and Physical Education through generous grants from the Royal Norwegian Ministry of Culture, the Norwegian Olympic Committee and Confederation of Sport, Norsk Tipping, and Pfizer. In addition, this study was supported by grants from the Norwegian
Sports Medicine Foundation, the Norwegian Handball Federation, and If insurance.

Ethical approval: Ethical approval was not required by the regional committee for medical research ethics.

1 Pate RR, Pratt M, Blair SN, Haskell WL, Macera CA, Bouchard C, et al. Physical activity and public health. A recommendation from the Centers for Disease Control and Preand public health. A recommendation from the Centers for Disease Control and
vention and the American College of Sports Medicine. JAMA 1995;273:402-7.

2 Fention and the American College of Sports Medicine. JAMA 1995;273:402-7. ment on exercise: benefits and recommendations for physical activity programs for all Americans. A statement for health professionals by the Committee on Exercise and Cardiac Rehabilitation of the Council on Clinical Cardiology, American Heart Association. Circulation 1996;94:857-62.

3 Bahr R, Kannus P, van Mechelen. Epidemiology and prevention of sports injuries. In: Kjær M, Krogsgaard M, Magnusson P, Engebretsen L, Roos H, Takala T, et al. Textbook of sports medicine. Basic science and clinical aspects of sports injury and physical activity. Blackwell Science, 2003:299-314,

4 Arendt E, Dick R. Knee injury patterns among men and women in collegiate basketball and soccer. NCAA data and review of literature. Am J Sports Med 1995;23:694-701.

5 Myklebust G, Maehlum S, Engebretsen L, Strand T, Solheim E. Registration of cruciate Myklebust G, Maehlum S, Engebretsen L, Strand T, Solheim E. Registration of cruciate
ligament injuries in Norwegian top level team handball. A prospective study covering two seasons. Scand J Med Sci Sports 1997;7:289-92

6 Powell JW, Barber-Foss KD. Sex-related injury patterns among selected high school sports. Am J Sports Med 2000;28:385-91.

7 Myklebust G, Bahr R. "When can I play again, Doc" vs. "Is it time to quit"-a critical look at return-to-play guidelines after ACL surgery. Br J Sports Med (in press).

8 Caraffa A, Cerulli G, Projetti M, Aisa G. Prevention of anterior cruciate ligament injuries in soccer. A prospective controlled study of proprioceptive training. Knee Surg Sports Traumatol Arthroscopy 1996;4:19-21.

9 Bahr R, Lian O, Bahr IA. A twofold reduction in the incidence of acute ankle sprains in volleyball after the introduction of an injury prevention program: a prospective cohort volleyball after the introduction of an injur
study. Scand J Med Sci Sports 1997;7:172-7.

10 Myklebust G, Engebretsen L, Braekken IH, Skjolberg A, Olsen OE, Bahr R. Prevention of ACL injuries in female team handball players - a prospective intervention study over three seasons. Clin J Sport Med 2003;13:71-8.

11 Wedderkopp N, Kaltoft M, Lundgaard B, Rosendahl M, Froberg K. Prevention of injuries in young female players in European team handball. A prospective intervention study. Scand J Med Sci Sports 1999;9:41-7.

12 Hewett TE, Lindenfeld TN, Riccobene JV, Noyes FR. The effect of neuromuscular training on the incidence of knee injury in female athletes. A prospective study. Am J Sports Med 1999;27:699-706.

13 Heidt RS Jr, Sweeterman LM, Carlonas RL, Traub JA, Tekulve FX. Avoidance of soccer injuries with preseason conditioning. Am J Sports Med 2000;28:659-62.

14 Junge A, Rosch D, Peterson L, Graf-Baumann T, Dvorak J. Prevention of soccer injuries: a prospective intervention study in youth amateur players. Am J Sports Med 2002;30:652-9.

15 Nielsen AB, Yde J. An epidemiologic and traumatologic study of injuries in handball. Int J Sports Med 1988:9:341-4.

16 Lin DY, Wei DJ. The robust inference for the Cox proportional hazards model.J Am Stat Assoc 1989;84:1074-8.

17 Ebstrup JF, Bojsen-Moller F. Anterior cruciate ligament injury in indoor ball games. Scand J Med Sci Sports 2000;10:114-6.

18 Olsen OE, Myklebust G, Engebretsen L, Bahr R. Injury mechanisms for anterior cruciate ligament injuries in team handball: a systematic video analysis. Am J Sports Med 2004;32:1002-12.

19 Holm I, Fosdahl MA, Friis A, Risberg MA, Myklebust G, Steen H. Effect of neuromuscular training on proprioception, balance, muscle strength, and lower limb function in female team handball players. Clin J Sport Med 2004;14:88-94

20 Hewett TE, Stroupe AL, Nance TA, Noyes FR. Plyometric training in female athletes. Decreased impact forces and increased hamstring torques. Am J Sports Med 1996;24:765-73.

21 Mjolsnes R, Arnason A, Osthagen T, Raastad T, Bahr R. A 10-week randomized trial comparing eccentric vs. concentric hamstring strength training in well-trained soccer players. Scand J Med Sci Sports 2004;14:311-7.

22 Chappell JD, Yu B, Kirkendall DT, Garrett WE. A comparison of knee kinetics between male and female recreational athletes in stop-jump tasks. Am J Sports Med 2002;30:261-7.

23 Fagenbaum R, Darling WG. Jump landing strategies in male and female college athletes and the implications of such strategies for anterior cruciate ligament injury. Am J Sports Med 2003;31:233-40.

(Accepted 30 November 2004)

doi 10.1136/bmj.38330.632801.8F

Oslo Sports Trauma Research Center, Norwegian University of Sport and Physical Education, 0806 Oslo, Norway

Odd-Egil Olsen research fellow

Grethe Myklebust research fellow

Lars Engebretsen professor

Ingar Holme professor

Roald Bahr professor

Correspondence to: O E Olsen odd-egil.olsen@nih.no 